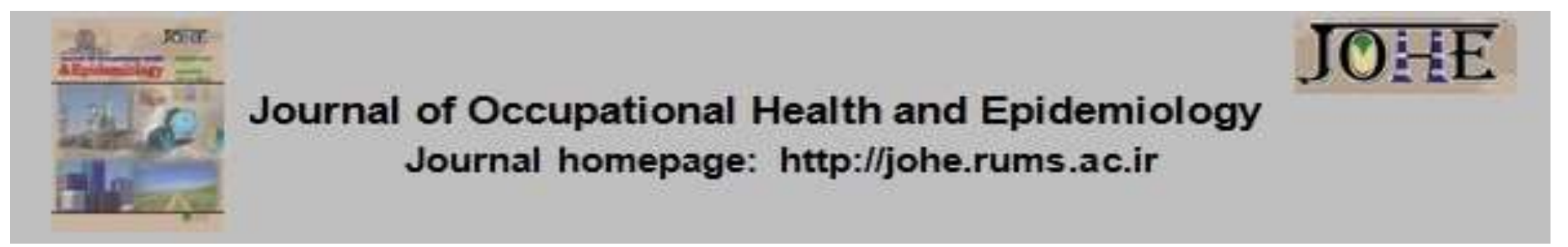

\title{
Back Compressive Force (BCF) assessment using UTAH method in manual handling tasks among workers of a chemical manufacturing company
}

\author{
Mahbobeh Abedi ${ }^{1}$, Ayoub Ghanbary Sartangi², Ehsanollah Habibi ${ }^{3}$, Feizollah Palyzban ${ }^{4}$, Hamed \\ Ghasemi ${ }^{5}$ \\ 1- MSc in Health Safety Environmental Management, Islamic Azad University Tehran Medical Unit, Tehran, Iran. \\ 2- MSc in Occupational Health Engineering, School of Health, Isfahan University of Medical Sciences, Isfahan, Iran. \\ 3- Professor, Department of Occupational Health Engineering, School of Health, Isfahan University of Medical Sciences, Isfahan, \\ Iran. \\ 4- BSc in Occupational Health Engineering, Ilam University of Medical Sciences, Ilam, Iran. \\ 5- BSc in Petroleum Engineering, Azad University of Firuzabad, Firuzabad, Iran.
}

\section{Article Info \\ * Corresponding authors: Ayoub Ghanbary Sartang, E-mail: aioobghanbary@ymail.com \\ Article history \\ Received: Sep, 2018 \\ Accepted: Dec, 2018 \\ 10.29252/johe.7.4.222}

Print ISSN: 2251-8096 Online ISSN: 2252-0902

Peer review under responsibility of Journal of Occupational Health and Epidemiology
Citation: Abadi M, Ghanbary Sartang A, Habibi E, Palyzban F, Ghasemi H. Back Compressive Force (BCF) assessment using UTAH method in manual handling tasks among workers of a chemical manufacturing company. JOHE. 2018; 7(4):222-6.

\section{Introduction}

Manual handling tasks are extensively performed in many occupations. Manual load handling is one of the several factors causing work-related musculoskeletal disorders in the construction industry and causes serious issues with major economic consequences. Also, musculoskeletal disorders are one of the most commonly diagnosed diseases and occupational injuries in the world and have different effects on different parameters of physical and mental health of workers in different

\begin{abstract}
Background: Job back pain is of the most common occupational injuries in the world that affects people's physical and mental health. The purpose of this study was to assess back compressive force (BCF) in manual handling tasks among workers of a chemical manufacturing company using the UTAH method.
\end{abstract}

Materials and Methods: This descriptive study was carried out on a group of 35 workers doing manual handling tasks in a chemical factory that were selected through simple random sampling in April and May 2018. The data collected by UTAH method and Cornell questionnaire, were analyzed in SPSS 19. Descriptive and inferential statistics methods including analysis of variance (ANOVA) were applied.

Results: The average BCF value calculated using the UTAH method showed that the load pressure on back for the jobs of repair unit $(400 \mathrm{~kg})$, discharge and loading unit $(460 \mathrm{~kg})$, Cornell questionnaire indicated that 68 percent $(N=24)$ of the workers in the mentioned occupations were suffering from lower back pain.

Conclusion: The findings of this study showed that the UTAH method is useful for estimating the BCF in manual handling tasks. Interventions should be conducted and measures should be taken to reduce these disorders.

Keywords: Disease, Back Pain, Chemical. 
handling are at high risk of musculoskeletal symptoms, injuries, and disorders, and the risk of secondary disability have also been dramatically increased among such personnel (4) Musculoskeletal disorders, muscular disorders, jaundice, peripheral nerves, joints, bones, ligaments result from repeated motions, awkward postures and excessive force over time, or result from an instantaneous or acute beat (5). In general, the risk factors underlying musculoskeletal disorders are divided into three general categories: demographic factors, occupational (environment and work equipment), and psychosocial factors (4). In a study that evaluated and management of chronic workrelated musculoskeletal disorders of the distal upper extremity, Piligian et al. Concluded that repetitive motion were the main causes musculoskeletal disorders (6) In a study conducted in 2007, lifting and carrying heavy loads was introduced as one of the main causes of musculoskeletal discomfort (7). Medical evidence suggests that effective ergonomic interventions can reduce the physical needs for manual handling of loads, thereby reducing the number and severity of relevant injuries. In a study by Panjali et al, manual handling was found as the main cause of most of work-related lumbar injuries (8). According to the NIOSH report, about half a million workers in the United States suffer from various degrees of lumbar damage every year. The report suggests that about $60 \%$ of the compensation for physical damage is related to manual handling activities (9). Different methods have been proposed for assessing the compressive force on the lower back. One of these methods is the UTAH method introduced in 2000 by Bloswick et al at Utah University and the back compressive force (BCF) is $320 \mathrm{~kg}$ or $700 \mathrm{lbs}$ (10). In all risk assessment methods, manual handling of biomechanical agents is very important. The workplace biomechanical variables such as weight, spacing, and position of work stations are effective in the prevalence of musculoskeletal disorders (11). Currently, work-related musculoskeletal disorders (WMSD) represent a serious issue with major economic implications. The World Health Organization considers work-related musculoskeletal disorders as multifactorial diseases, and showed a number of factors that increase the risk of diseases and the incidence of these injuries. One of the most common musculoskeletal disorders caused by manual handling, especially lifting, is damage to the lumbar region. Musculoskeletal disorders and occupational back pain have also a high prevalence in the workplace, and are the main cause of the economic damages caused by industrial enterprises and the reduction of labor productivity and absenteeism.
The purpose of this study was to evaluate back compressive force (BCF) in manual handling tasks among workers of a chemical manufacturing company using the UTAH method.

\section{Materials and Methods}

This descriptive-analytical and cross-sectional study was conducted in 2018 in Ilam Province. In The employees working in the company were 50 in total, of who 35 employees were selected through simple random sampling as the respondents in the study. The respondents were all males and worked in different jobs and carried out manual handling tasks with workloads of 10 to 30 kilograms including tasks involved manual handling on the ground and moving and placing the loads in the desired locations.

The criterion to enter to the study was having at least six months of work experience. The exclusion criteria were the employee's unwillingness to participate in the study and not having manual handling tasks in their jobs (3). UTAH method was introduced in 2000 by Bloswick et al at Utah University to measure the compressive force inserted on the back, and the permissible back compressive force (BCF) is $320 \mathrm{~kg}$ or $700 \mathrm{lbs}$. The Utah method uses the load weight, body weight, and back angle to calculate the amount of compressive force on the lower back and vertebrae of L5 to S1. The validity of this method has been confirmed in a study by Saraiani et al $(9,10)$. The back compressive force (BCF) is calculated using the following equation (11):

$F C=3(B W) \sin \alpha+0.05(L \times H B)+0.80((B W) / 2+L))$

Where, $\mathrm{Fc}_{\mathrm{c}}$ is the force compressive (KG), BW is the body weight (KG), Sin $\alpha$ is the back twist angle from 0 to 90 degree, $L$ stands for the load $(\mathrm{kg})$, and HB is the horizontal body $(\mathrm{m})$.

The Cornell Musculoskeletal Discomfort Questionnaire (CMDQ) was used to determine the prevalence of musculoskeletal disorders among the respondents for the past 12 months. The reliability and validity of the questionnaire were checked confirmed in a study by Afife Zadeh et al. (12) and Cronbach's alpha value for this questionnaire was 0.98 (12). First, the respondents' demographic data including their age, work experience, and education level were collected by the researcher by referring to the work environment. Then, the data related to the variables of the UTAH method were collected and finally, the Cornell Musculoskeletal Discomfort Questionnaire (CMDQ) was completed by the respondents. Ethical considerations in this study were considered by observing the confidentiality of 
the respondents' personal information. The collected data were analyzed SPSS 19 software through descriptive statistics and infertial statsitics including the analysis of variance (ANOVA) at the significance level of $0.05(P=0.05)$.

\section{Results}

Table 1 shows the descriptive statistics for the respondents in terms of their occupations.

Table 1: The number of the respondents by occupation

\begin{tabular}{lc}
\hline Working units & $\begin{array}{l}\text { Number of } \\
\text { employees }\end{array}$ \\
\hline Repair & 7 \\
\hline Discharge and loading & 8 \\
\hline Storage and warehousing & 15 \\
\hline Quality control & 5 \\
\hline
\end{tabular}

Of the 35 respondents in this study, 15 persons held a secondary school diploma or were at lower levels while 20 persons were above the secondary school education. Table 2 shows the descriptive statistics for respondents' age and their work experience:

Table 2: The descriptive statistics for respondents' age and their work experience

\begin{tabular}{lcc}
\hline \multicolumn{1}{c}{ Variable } & Mean (SD) & Min-Max \\
\hline Age (year) & $34.02(3.16)$ & $25-37$ \\
\hline $\begin{array}{l}\text { work experience } \\
\text { (year) }\end{array}$ & $3(0.95)$ & $1-3$ \\
\hline
\end{tabular}

Table 3 shows the average back compressive force (BCF) values measured by UTAH method for different occupations:

Table 3: The average BCF values measured by UTAH method for different occupations

\begin{tabular}{lcc}
\hline Working units & $\begin{array}{c}\text { Average BCF } \\
\text { (kg) }\end{array}$ & $\begin{array}{c}\text { Permissible } \\
\text { BCF (kg) }\end{array}$ \\
\hline Repair & 400 & 320 \\
\hline $\begin{array}{l}\text { Discharge and } \\
\text { loading }\end{array}$ & 460 & 320 \\
\hline $\begin{array}{l}\text { Storage and } \\
\text { warehousing }\end{array}$ & 370 & 320 \\
\hline Quality control & 200 & 320 \\
\hline
\end{tabular}

As it can be seen in Table 3, the average back compressive force (BCF) is under permissible limits only in the Quality Control Unit and the exerted back compressive force (BCF) in the other units was higher than the permitted level which is $320 \mathrm{~kg}$ according to the Utah method. The average BCF values in the repair, discharge and loading, storage and warehousing units are 400, 460, and 360, respectively, which exceed the permitted levels.

Also, according to the Cornell questionnaire, the percentage of people with back pain was presented separately in each job in Table 4.

Table 4 shows the number and percentage of workers suffering from back pain in different working units:

Table 4: The descriptive statistics for the workers suffering from back pain

\begin{tabular}{lcc}
\hline Working units & $\begin{array}{c}\text { The number of } \\
\text { workers with } \\
\text { back pain }\end{array}$ & Percentage \\
\hline Repair & 5 & 71 \\
\hline $\begin{array}{l}\text { Discharge and } \\
\text { loading }\end{array}$ & 7 & 87 \\
\hline $\begin{array}{l}\text { Storage and } \\
\text { warehousing }\end{array}$ & 11 & 73 \\
\hline Quality control & 1 & 20 \\
\hline
\end{tabular}

As it can be seen in the table above, the highest and lowest numbers of workers with back pain are in the storage and warehousing unit and the quality control unit, respectively.

Finally, the ANOVA results showed no significant relationship between the respondents' age and back compressive force $(B C F)(P>0.05)$. However, there was a significant relationship between the respondents' work experience and back compressive force (BCF) $(P<0.05)$, as shown in Table 5:

Table 5: Relationship of the respondents' age and work experience with the back compressive force

\begin{tabular}{lc}
\hline \multicolumn{1}{c}{ Variable } & BCF (P-value) \\
\hline Age & 0.07 \\
\hline Work experience & 0.03 \\
\hline
\end{tabular}

\section{Discussion}

Many jobs involve manual lifting of loads. Such jobs put chemical company staff at the increased risk of musculoskeletal disorders. Incorrect lifting methods are an important risk factor for low back pain. The purpose of this study was to investigate the back compressive force (BCF) in manual handling tasks among workers of a chemical manufacturing company. The Utah method is very useful because it is simple and easy for estimation of back compressive force (BCF). The results of this study showed that people working in this company are at risk of back pain and should take intervention measures to reduce it. Turkman et al. [14] examined the back compressive force (BCF) in construction workers and concluded that back compressive force (BCF) among construction workers exceed the 
permitted limits. Also, the ANOVA results showed that there was no significant relationship between the respondents' age and the amount of back compressive force (BCF) tolerated by them. However, there was significant relationship between the respondents' work experiences and the amount of back compressive force (BCF). This finding is is consistent with the results of a study by Turkman et al. In the industrial sector, heavyweight loads with high frequency of movement can be a risk factor for job back pain. A study by Panjali et al. [8] showed that heavyweight load is an important factor for occupational back pain, which is consistent with the findings of the present study. Murshdi et al. [14] studied the back compressive force (BCF) using the 3DSSPP (3D Static Strength Prediction Program) software, and concluded that the highest back compressive force (BCF) among the hospital staffs was 6727 newton, the highest back compressive force (BCF) in the present study was $460 \mathrm{~kg}$ based on the Utah method. In their study, Gomez et al. [15] conducted biomechanical analysis of manual handling tasks in a manufacturing company using 3DSSPP software, and provided some recommendations such as redesigning lifting devices to reduce the pressure on the lower back and prevent damage and musculoskeletal injuries. The results of a study by Afshari et al. [16] showed that the back compressive force (BCF) in 85.6 percent people was higher than the permissible limit and the most common musculoskeletal disorders in these people were low back pain due to heavy physical tasks and stresses entering the back. In our study, $68 \%$ of the respondents had back pain. Asadi et al [17] evaluated the compressive force in the lower back using the 3 DSSPP (3D Static Strength Prediction Program) software and concluded that the compressive force on the lower back is higher than permissible limit $(3400 \mathrm{~N})$ in $17 \%$ of people (21 people). Also, $68 \%$ of the respondents (24 people) in the present study complained of back pain; a finding which is consistent with the results of the study by Asadi et al. [17]. Falaki et al. [18] investigated musculoskeletal disorders and lower back pain and concluded that $69.5 \%$ of people were suffering from lower back pain, and this finding was also supported by the data in the present study. Afshari et al. [5] concluded that compressive force in men was $21.8 \mathrm{meg} \mathrm{N}$. Sec and in women 13.13 mega $\mathrm{N}$.sec in weavers and estimating daily cumulative force can be an important indicator in the prevention of occupational low back pain.

Despite its valuable insights, the study was conducted with some limitations including the small number of participants in the study.

\section{Conclusion}

The results of this study showed that the level of back compressive force (BCF) was high among the company workers and they were at risk of job back pain, and interventions should be undertaken to reduce the potential disorders. Also, Utah method is a simple and easy method to estimate the amount of back compressive force (BCF) in manual handling tasks. By biomechanical analysis of work environments, a more precise assessment can be done quantitatively, and the ergonomic conditions of the work can be improved more accordingly.

\section{Acknowledgement}

This study was sponsored as a part of a research project under number 3512 approved by the professional health unit of the health center. The authors hereby express their sincere appreciation for all people involved in this research project, especially Mr. Palizban.

Conflict of interest: None declared.

\section{References}

1. Daenen L, Varkey E, Kellmann M, Nijs J. Exercise, not to exercise, or how to exercise in patients with chronic pain? Applying science to practice. Clin J Pain 2015; 31(2):108-14.

2. Verbeek J, Martimo KP, Karppinen J, Kuijer PP, Takala EP, Viikari-Juntura E. Manual material handling advice and assistive devices for preventing and treating back pain in workers: a cochrane systematic review. Occup Environ Med 2011; 69(1):79-80.

3. Faber GS, Kingma I, van Dieën JH. Effect of initial horizontal object position on peak L5/S1 moments in manual lifting is dependent on task type and familiarity with alternative lifting strategies. Ergonomics 2011; 54(1):72-81.

4. Karami Matin B, Mehrabi Matin A, Ziaei M, Nazari Z, Yarmohammadi H, Gharagozlou F. Risk assessment of cumulative trauma disorders in Quarry and Stone Industries workers Kermanshah in 2013. Journal of Ergonomics 2013; 1(2):28-35

5. Afshari D, Motamedzadeh M, Soltanian AR. Estimation of cumulative compression load on the L4/L5 lumbar of carpet weavers through direct measurement of trunk posture and direct observation during a shift work. Iran Occupational Health Journal 2015; 12(2):62-9.

6. Piligian G, Herbert R, Hearns M, Dropkin J, Landsbergis $P$, Cherniack $M$. Evaluation and management of chronic work-related musculoskeletal disorders of the distal upper extremity. Am J Ind Med 2000; 37(1):75-93. 
7. Ciriello VM, Dempsey PG, Maikala RV, O'Brien NV. Revisited: comparison of two techniques to establish maximum acceptable forces of dynamic pushing for male industrial workers. Int $J$ Ind Ergon 2007; 37(11-12):877-82.

8. Panjali Z, Mazloumi A, Ahsani H, Rezaee E. Evaluation of the risks for manual material handling in a metal casting industry in Iran. Iran Occupational Health Journal 2014; 11(1):13-22

9. Sarayani $\mathrm{MH}$, Rastegar I, Rostami M. Investigation the back pain and compression force on the back workers by UTAH method (Case Study: Sofal Sazan Morvarid Behshahr Company). Peper presented at: The2nd International Iranian Ergonomic Conference and $2^{\text {nd }}$ Biennial Iranian Conference on Ergonomics; 2016 Oct 19-21; Shiraz, Iran.

10. Merryweather AS, Loertscher MC, Bloswick DS. A revised back compressive force estimation model for ergonomic evaluation of lifting tasks. Work 2009; 34(3):263-72.

11. The Eastman Kodak Company. Kodak's ergonomic design for people at work. $2^{\text {nd }}$ ed. New York City, United States: John Wiley \& Sons, Inc; 2004. p.159-62.

12. Afifehzadeh-Kashani $H$, Choobineh $A$, Bakand $\mathrm{SH}$, Gohari MR, Abbastabar H, Moshtaghi P. Validity and reliability of farsi version of Cornell Musculoskeletal Discomfort Questionnaire (CMDQ). Iran Occupational Health Journal 2011; 7(4):69-75.

13. Torkaman J, Motamedzade M, Attari SGh, Roshanaei Gh. Assessment of compressive force on back of hamadan building construction workers during manual load handling by utah method in 2015: a short report. Journal of Rafsanjan University of Medical Sciences 2017; 16(8):797-804.

14. Morshedi R, Boazar M, Afshari D, Ahmadi Angali K, Malek Zadeh M. Biomechanical analysis of manual lifting of loads and ergonomics solutions for nursing assistants. Journal of Ergonomics 2015; 3(1):17-24.

15. Gomez-Bull K, Ibarra-Mejia G, HernandezArellano JL. Biomechanical analysis of a manual materials handling task in a local manufacturing company. Peper presented at: The $1^{\text {st }}$ Annual World Conference of the Society for Industrial and Systems Engineering; 2012 Sep 16-18; Washington, DC, USA.

16. Afshari D, Mohammadi A, Saki A, Movafaghpour M. Continuous monitoring of back postures using portable inclinometer among nursing assistants. Iran Occupational Health Journal 2014; 11(3):309.

17. Asadi N, Choobineh A, Keshavarzi S, Daneshmandi $\mathrm{H}$. Estimation of forces exerted on the lower back in manual load lifting using 3DSSPP software. Journal of Ergonomics 2015; 2(4):25-31.

18. Falaki S, Akbari H, Derakhshan M, Hannani M, Motalebi Kashani M. Prevalence and postural risk factors associated with musculoskeletal disorders among medical laboratory personnel in Kashan 2012. Iran Occupational Health Journal 2016; 12(6):58-68. 